\title{
Editorial
}

\section{PERMEANDO PAISAGENS}

Na chamada para a edição v. 12, n. 28 (2020) da Revista Palíndromo intitulada CORPO PERCURSO PAISAGEM, recebemos um grande número de artigos de excelente qualidade explorando as possibilidades poéticas do movimento e reflexões do corpo, percursos e paisagens como parte de processos artísticos. Parte dos artigos recebidos foram publicados em janeiro deste ano, e o segundo grupo de textos selecionados foram organizados nesta edição sob o título Permeando Paisagens.

A ideia de "permear paisagens" emergiu da frase de Francesco Careri: "A paisagem nasce nômade e de cabeça para baixo", no seu texto De cabeça para baixo (2017, p.126). Então, dando sequência às publicações anteriores, nesta edição da Palíndromo reunimos artigos que ampliam a noção de paisagem enquanto representação da natureza, e nos possibilitam olhar em volta, fazendo interrelações, ecoando significações espaciais, e seguindo por uma clareira mais abrangente que toma forma enquanto se abre, como escreve Careri:

[...] parte da natureza, parte do mistério ainda inexplicável, que agora já engloba também espaços que nós mesmos produzimos. Para conseguir ver esses espaços não basta inverter o olhar, é preciso colocar-se na condição graças à qual aquela paisagem possa desvelar-se, fazer mais um esforço contra o nosso corpo: é preciso ir lá, caminhar nela, mergulhar nela sem preconceitos culturais, fazer dessa paisagem uma experiência direta." (idem, p.127)

Os artigos aqui presentes consistem assim, de espaços e paisagens que se desvelam a leitor/e/as que se dispuserem a percorrer seus caminhos, se despindo de padrões preestabelecidos. Propomos aqui um mergulho em novas maneiras de olhar paisagens urbanas, zonas rurais, paisagens domésticas, paisagens pictóricas, enfim penetrar estas múltiplas dimensões transfiguradas por espaços subjetivos afetados pelo mundo a nossa volta.

\section{SEÇÃO TEMÁTICA}

No artigo Intervenção artístico-performática em praça pública de Florianópolis: um estímulo para a amabilidade urbana, os autores: Luize Andreazza Bussi, Maicon Douglas Livramento Nishimura, Mariana Silva Villela e Rodrigo Gonçalves dos Santos apresentam uma pesquisa sobre relações pessoais e espaciais urbanas, realizada por meio de uma intervenção artístico-performática de caráter temporário, em praça pública da cidade de Florianópolis, SC. A intervenção baseou-se no conceito de amabilidade urbana cunhado por Adriana Sansão Fontes, com o objetivo principal de 
promover relações de proximidade e intimidade entre pessoas, e entre pessoas e espaço, buscando ativar um equipamento urbano aparentemente subutilizado. A pesquisa aplicou as oito dimensões da intervenção temporária propostas por Fontes: transitória, pequena, particular, participativa, relacional, ativa, interativa e subversiva

Em A casa enquanto paisagem na obra de artistas brasileiras: Rosana Paulino, Conceição Evaristo e Aline Motta, a autora Lorena Galery Batista a partir da leitura de obras, relatos orais e textos teóricos, pretende investigar o quintal e o espaço doméstico enquanto paisagem, ativados poeticamente pela imagem da mãe (e ancestralidades em geral), na obra de três artistas/autoras brasileiras da contemporaneidade: Conceição Evaristo, Rosana Paulino e Aline Motta. Articulando a teoria feminista negra brasileira e afroamericana com os conceitos de cartografia psicossocial trabalhados por Suely Rolnik, pretende-se traçar possibilidades de leitura dessas obras que podem não corresponder às ferramentas tradicionais de crítica de arte.

No artigo Transporto sentimentos, a autora Viviane Vallades da Silva descreve o processo criativo da obra Transporto sentimentos, de sua autoria. Durante a descrição, realiza passagens de pensamentos que refletem sobre a ação e percurso de seu corpo em diferentes paisagens. Discorre também sobre possibilidades de ação na paisagem da cidade através da prática artística, ruídos que uma ação pode causar assim como as indagações sobre tal ato.

Em Subversão e dependência das tecnoimagens: paisagem e câmara escura na arte atual, os autores Rodrigo Hipólito e Fabiana Pedroni falam sobre a construção de câmaras escuras para o estudo da paisagem na Arte atual. Com tal foco, pensam a estruturação da paisagem como da ordem da subjetividade através do conceito de stimmung, de Georg Simmel, e estabelecem um diálogo com o sentido de tecnoimagem, de Vilém Flusser. Diante da experiência do sujeito com o "recorte" instituído pelas tecnoimagens e da larga disseminação permitida pela reprodução digital, pensam os trabalhos de Abelardo Morell e Nilu Izadi como estratégias de subversão do olhar fotográfico. Tal subversão exigiria a presença do indivíduo como parte da construção e revelação do sentido da paisagem. Inclui-se, neste texto, a pergunta pelos limites das estratégias dos artistas citados, tendo em vista que a sobrevivência, difusão e estudo destas obras dependem, em certo nível, da produção e contato do público com tecnoimagens.

O artigo Um caderno de viagem, de Marcelo Eugenio Soares Pereira, investiga alguns aspectos formais e conceituais de um caderno de viagem, desenvolvido pelo autor entre os anos de 2013 e 2014. A metodologia, de ordem qualitativa e exploratória, baseia-se na análise de alguns dos desenhos nele presentes. Tais análises são amparadas por contribuições advindas do campo da história da arte e sua relação com o passado segundo Kern (2013). No que concerne à temática dos cadernos de viagem e dos artistas viajantes, baseia-se nas reflexões de Dourado da Silva (2013), Pesavento (2007) e Taquelim (2008). Além disso, aborda algumas implicações de ordem estética a partir do pensamento de Gumbrech (2006). Desse modo, visa reconhecer a relevância e atualidade da prática do caderno de viagem como espaço de experimentação plástica e exercício de um olhar mais atento ao entorno.

No artigo Deslocamentos no espaço: representações da paisagem na pintura 
do século XXI no Brasil, os autores Francis Rodrigues da Silva e Luciana Martha Silveira apontam que no século $X X I$, o conceito de paisagem e sua representação na pintura continuam se transformando, inclusive em produções brasileiras. Nelas, há um diálogo com a vivência na paisagem brasileira, seus biomas e processos urbanísticos desorganizados. A partir de experiências e deslocamento nesses espaços, os artistas produzem imagens abordando questões mostrando os impasses culturais do país. Os autores investigam neste artigo a relação entre a experiência de deslocamento no espaço com a representação da paisagem na produção de pintura do século XXI no Brasil, tratando dos processos artísticos envolvidos nessas produções. Para isso, observaram obras de artistas que têm o deslocamento no espaço como parte do processo de produção de pintura como: Miguel Penha, David Almeida, Luiz Zerbini e Marina Rheingantz.

Em Gambiarra e outros métodos para esculpir uma paisagem: modos de pensar e produzir arte a partir da vida no campo, os autores Pedro Elias Parente da Silveira e Eduarda Azevedo Gonçalves Correio apresentam prospecções entorno de gambiarras sulinas e modos de vida encontrados na zona rural de Piratini, interior do Rio Grande do Sul, e que funcionam como motivadores de uma pesquisa desenvolvida no Programa de Pós-Graduação em Artes Visuais da Universidade Federal de Pelotas na linha de Processos de Criação e Poéticas do Cotidiano.

\section{SEÇÃO ABERTA}

No artigo Distração, recolhimento, planaridade e afetação geral: a reestruturação da recepção na arte moderna, autor Filipe Ferreira Pires Volz nos conta que no ensaio A obra de arte na era de sua reprodutibilidade técnica, primeira versão, Walter Benjamin descreve dois modos de recepção da obra de arte, o 'recolhimento (recepção ótica) e a distração (recepção tátil). Este artigo conta com dois objetivos: mostrar como historicamente esses dois modos configuraram a relação do espectador com as obras de arte em épocas distintas; a partir do entendimento das mudanças artístico-sociais do século XX propor uma conceituação para o modo mais próprio de recepção de obras de arte hoje.

O artigo A crítica de arte no entrecruzamento da palavra com a imagem, de autoria de Lindomberto Ferreira Alves parte de uma elaboração de caráter geneológica, que recupera os percursos teóricos da crítica de processos criativos, busca-se perscrutar, a partir dos aspectos que atravessam seus procedimentos teórico-críticos, caminhos possíveis aos desafios enfrentados pela crítica de arte ante a intrincada relação obra-processo tensionada pela poética artística contemporânea.

Em Não fale bobagens: interferências textuais na fotografia, a autora Havane Maria Bezerra de Melo busca apresentar a participação da tipografia na arte contemporânea por meio da produção autoral de fotografias ficcionais, utilizando como referência os artistas Mona Hatoum e Ed Rusha e os diretores de cinema Quentin Tarantino e Robert Rodriguez, além de personagens marcantes da cultura pop, tais como Dr. Zaius (Planeta dos Macacos), Mulher Maravilha, Jack Brown, Uhura (Jornada nas Estrelas: a série clássica) e mais dez personagens femininas da coleção Grindhouse. Como assunto principal das quatro fotografias construídas, temos o protagonismo feminino levan- 
tando questões sobre a posição da mulher na sociedade contemporânea. A interferência da palavra na imagem dá-se através da escolha planejada de frases e tipografias trabalhadas de forma harmônica com a fotografia. Como resultado, são apresentadas quatro obras autorais que utilizam como linguagem principal a fotografia de ficção, criadas unicamente com a finalidade de provocar reflexões acerca de questões predominantemente femininas.

No artigo Notas sobre possíveis origens da comunicação humana, o autor Marcos H. Camargo nos conta que a arte da comunicação humana dependeu do desenvolvimento de códigos baseados na intencionalidade compartilhada entre os grupos, evoluindo dos gestos indicativos e miméticos para signos mais complexos, até alcançar a linguagem verbal, dentre outros sistemas de signos que comportam a cultura humana. Palavras, números, imagens, música, gestos, enfim, uma grande variedades de signos compõem as linguagens da cultura, com as quais os humanos produzem seus conhecimentos, como sua arte.

Em Imagens moralmente ilustrativas, o autor Eduardo Gonçalves Diastraz ao debate a fotografia (e sua mestiçagem com outras artes), e o modo como ela tem sido manipulada com a função de alterar a percepção de realidade desde meados do século 20 , tendo como consequência reflexos na política e no comportamento da sociedade contemporânea. Como metodologia foi adotada a leitura de teóricos sobre o conceito de hiper-realidade, a visualização de obras de arte e movimentos durante esse período, e sua atual repercussão e discussão, no meio filosófico, artístico e social. O mote de tal investigação é o termo "imagem meramente ilustrativa" e a dissimulação com que se é tratado o assunto: tema de extrema importância, apesar das letras pequenas.

\section{ENTREVISTAS}

Em $O$ encontro poético do eu e o outro: entrevista com Elisa Castro por Ynaê Cortez, a autora Ynaê Cortez de Morais objetiva refletir sobre questões acerca da Arte e o Outro e suas emanações na obra da artista contemporânea Elisa Castro. Esse diálogo problematiza a posição do artista como criador e analisa as proposições de experiências interpessoais e coletivas. As propostas artísticas que são abordadas nesta entrevista são proposições, questionando a passividade dos expectadores e os convocam a participar da criação e ativação das obras. A entrevista investiga a potencialização do diálogo e da escuta do outro, nos encontros poéticos propostos pela artista.

$\mathrm{Na}$ entrevista Cartografando a matéria: uma entrevista com o artista Sindri Mendes sobre a exposição 'devir', a autora Vanessa Seves Deister de Sousa nos conta sobre a exposição "Devir" que foi idealizada pela curadora Cecília Cánepa e permaneceu aberta ao público entre os meses de março e abril de 2017 no "Museo de Arte Contemporaneo Latinoamericano - MACLA" na cidade de La Plata, Argentina. A exposição contou com centenas de objetos elaborados pelo artista visual paraense Sindri Mendes que também participou da organização da mostra. Em "Devir", Sindri apresenta ao público pinturas, esculturas, instalações e construções em vídeo desenvolvidas durante um percurso poético de pelo menos sete anos. Na entrevista, o artista comenta detalhes sobre seu processo criativo, referências utilizadas para a elaboração das pe- 
ças, dentre outras falas que podem contribuir para a expansão do olhar a respeito da pesquisa em arte no chamado "campo ampliado" da arte contemporânea.

\section{PROPOSIÇÕES, REGISTROS E RELATOS ARTÍSTICOS / ENSAIOS VISUAIS}

O ensaio visual A ranhura da alma cria a fenda do sufoco, de autoria de Felipe Rodrigo Caldas, Maria Fernanda Mioranza dos Santos e Caio Eduardo Kulkamp de Paula é constituído de oito fotografias e foi produzido durante a disciplina Projeto em Corpo Artístico do curso de Arte da Universidade Estadual do Centro Oeste - UNICENTRO e apresenta a temática "O Corpo nas Ranhuras". Após leituras de autores como David Le Breton em específico seu livro "A Sociologia do Corpo" (1992) onde são abordados assuntos que apresentam a corporeidade humana enquanto fator social, sendo o corpo uma realidade mutante, um fato do imaginário social, um elemento de ligação com a energia coletiva e espaço para expressão de ideias. A Teoria do "Corpomídia"(2002) de Helena Katz e Christine Greiner, que trata do saber corporal adquirido nas relações de troca estabelecidos com o espaço também fundamentaram conceitualmente a ação.

\section{AUTORES CONVIDADOS}

Em Eu te darei o céu, meu bem - permanência, o autor Danillo Gimenes Villa apresenta o ensaio visual: Eu te darei o céu, meu bem - permanência. 32 fotos de 32 dias em que ele visita uma galeria e descola, de uma parede, uma foto gigante de um objeto que voa em uma paisagem rural. Após alguns dias repetindo a ação, não reconhecia mais o que a imagem registrava. A galeria, vazia e lavada, passou a guardar uma paisagem incomunicável. $O$ autor procurava o que Deleuze chamaria de a sutileza insubstituível do associacionismo. A imagem em questão foi capa do N. 26 CORPO PERCURSO PAISAGEM da Revista Palíndromo.

No ensaio visual Paisagens em Iracema, a autora Elke Pereira Coelho Santana cria um conjunto de fotografias realizadas com máquinas polaroides a partir de detalhes da paisagem. Apreendidas em situações e lugares distintos, e permeadas por certo anacronismo inerente ao aparato técnico empregado, as imagens estabelecem relações com a memória ao mesmo tempo em que almejam aproximações metafóricas com a ideia de afeto e de solidão.

Sandra Maria Correia Favero (PPGAV-UDESC)

Silvana Barbosa Macêdo (PPGAV-UDESC)

Organizadoras do Dossiê

Gabriel Augusto de Paula Bonfim

Editor de apoio

BIBLIOGRAFIA:

CARERI, Francesco. Caminhar e parar. São Paulo: Gustavo Gili, 2017. 